\title{
CONGENITAL, MALFORMATIONS
}

\section{MANAGEMENT OF CRANIOSYNOSTOSIS}

The safety and efficacy of early treatment of craniosynostosis, using minimally invasive endoscopic strip craniectomies, were evaluated prospectively in 100 patients (72 boys, 28 girls) treated at the University of Missouri Hospital, Columbus, MO. Ages ranged between 2 weeks and 9.5 months (mean 3.1 months); 63 were treated under 16 weeks of age. Of 106 stenosed sutures, 61 were sagittal, 23 coronal, 18 metopic, and 4 lambdoid. After surgery, all patients were fitted with custom-made molding helmets worn for up to 7 months. Follow-up ranged from 4 to 50 months. Mean surgical operative time was 52.7 minutes, and mean estimated blood loss was $26.2 \mathrm{ml}$. One patient required an intraoperative blood transfusion and 9 required postoperative transfusions. All except 3 patients were discharged on the first postoperative day, and without significant complication. This minimaliy invasive method of treatment is safe and effective and superior to the current more extensive surgical procedures. The optimal time for operation is under 6 months, preferably at 3 months. The majority achieve normocephaly or significant correction. (Jimenez DF, Barone CM, Cartwright CC, Baker L. Early management of craniosynostosis using endoscopic-assisted strip craniectomies and cranial orthotic molding therapy. Pediatrics July 2002;110:97-104). (Reprints: David F Jimenez MD, Division of Neurological Surgery, University Hospital and Clinics, One Hospital Drive, Columbia, MO 65212).

COMMENT. Sagittal synostosis has a reported incidence of 1 in 1000 live births. Coronal and metopic forms are less common and lambdoid craniosynostosis is rare. Optimal time for operation recommended for sagittal synostosis is usually at 3 to 4 months, and later for the other varieties. The less invasive method described by Jimenez et al appears safe and effective when employed at an early age. However, as pointed out by Maugans TA in an editorial (The misshapen head. Pediatrics July 2002;110:166-167), the minimal surgery is followed by an absolute requirement of weeks to months of cranial orthosis use. In the more extensive cranial remodeling surgery, optimal cosmetic results are realized immediately after postoperative swelling subsides and helmets are not usually required.

\section{SEIZURE DISORDERS}

\section{INTERLEUKIN GENE MARKER FOR FEBRILE SEIZURES}

The use of polymorphisms for interleukin 1B (IL-1B) exon 5 and interleukin 1 receptor antagonist (IL-1Ra) as markers of susceptibility to febrile seizures was evaluated in Taiwanese children (group 1: 51 with febrile convulsions and group 2: 83 normal controls) at China Medical College Hospital, Taichung, Taiwan. Genotype proportions and allele frequencies in the 2 groups were not significantly different for IL-1B exon 5, but were significantly different for IL-1Ra. Frequencies of alleles I and II for IL-1Ra were $100(98 \%)$ and 2 (2\%) in group 1 and $152(91.6 \%)$ and $14(8.4 \%)$ in group 2. The IL-1 Ra allele I is associated with a higher susceptibility to febrile convulsions. (Tsai F-J, Hsieh Y-Y, Chang C$\mathrm{C}$, et al. Polymorphisms for interleukein $1 \mathrm{~B}$ exon 5 and interleukin 1 receptor antagonist in Taiwanese children with febrile convulsions. Arch Pediatr Adolesc Med June 2002;156:545-548). (Reprints: Fuu-Jen Tsai MD PhD, Department of Pediatrics and Medical Genetics, China Medical College Hospital, 2 Yuh-Der Rd, Taichung Taiwan). 
COMMENT. Interleukin 1 receptor antagonist may be a useful marker for predicting susceptibility to febrile convulsions. In an editorial, Lewis DB of Stanford University comments that interleukin 1 was one of the first cytokines discovered and is an endogenous pyrogen (Arch Pediatr Adolesc Med June 2002;156:529-530). Febrile seizures may be added to the list of diseases associated with IL-1Ra polymorphisms. The frequency of IL1RN allele 2 is decreased in Taiwanese children with febrile convulsions compared with controls. However, the frequency of allele 2 in the case controls was lower than that reported in US and European studies. The finding should be confirmed in other populations.

Febrile convulsions and SIDS showed no shared susceptibility in a study of siblings of children with a history of febrile convulsions compared to siblings of children who never had a febrile convulsion. The rate of SIDS was 1.64/1000 person years in the two cohorts. There was no increased risk of SIDS in siblings of children hospitalized with a febrile convulsion. (Vestergaard $\mathrm{M}$ et al. Arch Dis Child 2002;86:125-127). A possible etiological relation between SIDS and febrile convulsions was suggested by Sunderland R, Emery J. (Lancet 1981;2:176-178). Hyperthermia is reported to be common in SIDS (Stanton AN. Lancet 2:1199-1201).

\section{ATTENTION DEFICIT DISORDERS}

\section{ATOMOXETINE OPEN-LABEL TRLAL IN ADHD}

Atomoxetine (originally named tomoxetine), a new therapy for attention deficit hyperactivity disorder (ADHD) marketed by Eli Lilly, was compared to methylphenidate in a prospective, randomized, open-label study for 10 weeks duration, at the University of Nebraska Medical Center, Massachusetts General Hospital, Mount Sinai Medical Center, Carolinas Medical Center, and Lilly Research Laboratories. Boys aged 7 to 15 years and girls aged 7 to 9 who met DSM-IV criteria for $\mathrm{ADHD}$ were admitted to the study. Of 228 patients randomized, 184 received atomoxetine and 44 methylphenidate. Atomoxetine was titrated to a maximum of 1 or $2 \mathrm{mg} / \mathrm{kg}$ per day, in 2 divided doses $\mathrm{AM}$ and late afternoon. Methylphenidate was initiated at $5 \mathrm{mg}$ one to three times daily, not to exceed $60 \mathrm{mg}$ daily. Both drugs resulted in marked improvement in inattentive and hyperactive-impulsive symptoms, with no significant differences in effectiveness and toxicity. ADHD-IV Rating Scale total scores were as follows: atomoxetine baseline 39.4 [8.5], endpoint 20 [13.9]; and methylphenidate baseline 37.6 [9.7], endpoint 19.8 [16.6]. Adverse events requiring drug withdrawal occur red in 10 of 184 (5.4\%) patients receiving amoxetine and $5 / 44(11.4 \%)$ for methylphenidate $(p=.175)$. Results of amoxetine treatment for ADHD are comparable to those of methylphenidate. (Kratochvil CJ, Heiligenstein JH, Dittmann $\mathrm{R}$ et al. Atomoxetine and methylphenidate treatment in children with ADHD: a prospective, randomized, open-label trial. 1 Am Acad Child Adolesc Psychiatry July 2002;41:776-784). (Reprints: Dr David Michelson, Lilly Corporate Center, DC 6026, Indianapolis, IN 46285).

COMMENT. Atomoxetine is an inhibitor of presynaptic norepinephrine transporter with minimal affinity for other noradrenergic receptors. Efficacy in children with $\mathrm{ADHD}$ has previously been demonstrated in 3 double-blind, placebocontrolled trials. The present study shows comparable efficacy to that of methylphenidate.

Atomoxetine is metabolized through the cytochrome P450 2D6 isoenzyme (CYP 2D6) pathway, with 2 phenotypes, one being rapid or extensive metabolizers 